\title{
Historia natural de Dioon merolae (Zamiaceae) en CHIAPAS, MÉXICO
}

\author{
Julia Manuela Lázaro-Zermeño ${ }^{1}$, Mario González-Espinosa ${ }^{2,5}$, Ana Mendoza ${ }^{3}$ \\ y Miguel Martínez-Ramos ${ }^{4}$ \\ 'Facultad de Ciencias Biológicas, Universidad de Ciencias y Artes de Chiapas \\ ${ }^{2}$ Departamento de Ecología y Sistemática Terrestres, División de Conservación de la Biodiversidad, \\ El Colegio de la Frontera Sur \\ ${ }^{3}$ Laboratorio de Ecología de Poblaciones Vegetales, Instituto de Ecología, Universidad Nacional Autónoma de México \\ ${ }^{4}$ Laboratorio de Ecología de Poblaciones y Comunidades Tropicales, \\ Centro de Investigaciones en Ecosistemas, Universidad Nacional Autónoma de México \\ ${ }^{5}$ Autor para la correspondencia: mgonzale@ecosur.mx
}

\begin{abstract}
Resumen: Se recopilan observaciones sobre la espadaña (Dioon merolae, Zamiaceae) de la Depresión Central (530-600 m) y de la Sierra Madre de Chiapas (1,100-1,200 m). Se visitaron entre 1997 y 2010 más de 800 individuos de distintos tamaños y en todas las etapas fenológicas. Se revisan las relaciones filogenéticas y distribución de D. merolae. A la descripción botánica original se agregan observaciones originales que permiten una mejor comprensión de sus relaciones ecológicas. Se revisa el crecimiento de los tallos desde la etapa de plántula hasta la etapa adulta, la producción de retoños en la base de los tallos, el crecimiento de la raíz, y la producción de hojas, estróbilos y semillas. Se discuten las interacciones entre esta especie vegetal y varios grupos animales implicados en la polinización, herbivoría y dispersión y depredación de las semillas. Se discute el efecto de incendios ocasionales sobre la supervivencia y la reproducción, así como la considerable longevidad y estimación de la edad de D. merolae. La especie enfrenta actualmente severos problemas para su conservación debido a una ceremonia religiosa popular que implica la defoliación completa (a veces parcial) de individuos adultos. Se discuten las implicaciones de esta práctica y algunas recomendaciones para el uso sustentable de la especie.
\end{abstract}

Palabras clave: Cycadales, espadaña, Eumaeus, fitómeros, Liomys.

\begin{abstract}
We compiled observations from six populations of Dioon merolae (Zamiaceae) located in the Central Depression (530$600 \mathrm{~m}$ ) and the Sierra Madre of Chiapas (1,100-1,200 m). More than 800 individuals of different size and in all phenological stages were visited during 1997 and 2010. A revision of the phylogenetical relationships and distribution of D. merolae is included, along with a botanical description complemented with original observations. The growth of stems is described from seedlings up to adult plants, as well as the production of basal suckers, root growth, and the production of leaves, strobili and seeds. Plant-animal interactions involved in pollination, herbivory, and seed dispersal and predation are described. The effects of occasional wild fires on survival and reproduction are discussed, as well as the longevity and age estimation of this long-lived species. D. merolae populations are severely threatened due to a local religious ceremony in which adult plants are heavily or almost completely (sometimes partially) defoliated. The conservation implications of this practice are discussed.
\end{abstract}

Key words: basal suckers, Cycadales, espadaña, Eumaeus, Liomys.

$\mathbf{E}$ conocimiento detallado de la historia natural de una especie es un precedente fundamental de los estudios autoecológicos y sinecológicos para, en su momento, proponer prácticas de aprovechamiento sustentable (Peters, 1996; Secrétariat of the Convention on Biological Diversity, 2001; Esparza-Olguín, 2004; Guariguata et al., 2008). En el caso de algunas especies de Zamiaceae de México se han logrado avances importantes en el conocimiento de su biogeografía (González-Astorga et al., 2003; Gregory y Chemnick, 2004; Vovides et al., 2004), sistemática (Vovides, 1983; Vovides et al., 1983; Vovides, 1985; Bogler y Francisco-Ortega, 2004; Schutzman, 2004; Nicolalde-Morejón, 2005), ecología (Vovides, 1990; Lázaro-Zermeño, 2002; Sánchez-Ramos et al., 2002; Vovides et al., 2003; Pérez-Farrera y Vovides, 2004; 
Pérez-Farrera et al., 2006; Lázaro-Zermeño et al., 2011), genética (Pérez-Farrera et al., 2007; Flores-Vázquez, 2008; Cabrera Toledo, 2009; Octavio-Aguilar, 2009), fisiología (Vovides et al., 2002a) y etnobotánica (Pérez-Farrera y Vovides, 2006; Valdez, 2009). Las poblaciones de Dioon merolae De Luca, Sabato y Vázquez-Torres (De Luca et al., 1981), y de otras Cycadales en México, se encuentran severamente amenazadas por cambios en el uso del suelo, por incendios y pastoreo derivados de las actividades humanas, y por prácticas de extracción inadecuadas de partes o individuos completos (Challenger, 1998; Pérez-Farrera y Vovides, 2006; Naranjo et al., 2009). Esto ha llevado a que todas las zamiáceas mexicanas se encuentren bajo alguna categoría de riesgo de acuerdo con la NOM-059 ECOL-2001 (SEMARNAT, 2002) o la IUCN (IUCN, 2001). En el caso de D. merolae, muchos elementos de su historia natural y las implicaciones demográficas de una antigua ceremonia religiosa en la que juega un papel central no han sido recopilados ni contrastados con los de especies cercanas. La incorporación de criterios e indicadores ecológicos, genéticos y sociales en el diseño y aplicación de prácticas de manejo sustentables de estas especies requiere de un conocimiento detallado sobre el mayor número posible de interacciones de estos organismos con su medio, incluida la sociedad. En este trabajo se integran observaciones originales sobre Dioon merolae relativas a su distribución espacial dentro y entre unidades del paisaje, morfología, crecimiento, reproducción, y sus interacciones con animales y con las comunidades humanas, realizadas durante varios años en poblaciones de la Depresión Central y la Sierra Madre de Chiapas. Las observaciones originales son complementadas con información de la literatura disponible sobre la biología de ésta y otras Zamiaceae. La información recopilada permite discutir elementos para el diseño de prácticas y planes de manejo que superen las amenazas para la persistencia de D. merolae y conduzcan a su aprovechamiento sustentable y conservación.

\section{Materiales y métodos}

Se revisó la literatura sobre las relaciones filogenéticas de Dioon merolae, apoyada en casos necesarios en información relativa al orden Cycadales, la familia Zamiaceae y el género Dioon. Se realizaron observaciones sobre tamaño poblacional, fenología, crecimiento del tallo, producción de hojas, retoños, conos y semillas en un total de 800 individuos entre 1997 y 2010 en varias poblaciones de $D$. merolae localizadas en la Depresión Central de Chiapas y una población localizada en la Sierra Madre de Chiapas. Las poblaciones de la Depresión Central fueron visitadas al menos cuatro veces al año. Los individuos fueron marcados y ubicados en un mapa dentro de parcelas de $10 \times 100 \mathrm{~m}$ para facilitar su relocalización y las observaciones. Las medidas de tallos y hojas y el conteo de éstas en las copas se realizaron con métodos no destructivos. Para definir la conexión entre los tallos a una misma raíz, se excavaron las raíces de cinco plantas con el cuidado de no dañar las plantas. Se recolectaron diez conos masculinos y seis femeninos para evaluar sus dimensiones y realizar observaciones detalladas de su estructura. Se marcaron los conos femeninos de 22 plantas para realizar observaciones periódicas hasta la liberación de las semillas. Se recolectaron semillas en tres ocasiones (al menos 200 semillas) para llevarlas a un jardín común en Jiquipilas (Chiapas) y realizar observaciones sobre la germinación y el desarrollo de las plántulas. En febrero de 2005 se recolectaron individuos de las especies de insectos que visitaban los conos femeninos, los cuales fueron llevados al laboratorio para su montaje y posterior determinación en el Instituto de Ecología, A.C. Se utilizaron 200 trampas Sherman durante tres noches en abril de 2009 para capturar las especies de roedores presentes en el sitio y que pueden dispersar y/o depredar las semillas. La estimación de la edad de los individuos adultos de $D$. merolae se realizó con un procedimiento basado en el publicado por Vovides (1990), a su vez derivado de Chamberlain (1911). El método aplicado en este estudio consiste en colocar sobre los tallos de $D$. merolae un cuadro de alambre de $5 \times 5 \mathrm{~cm}$ en la porción basal, media y apical del tallo; las bases persistentes de los pecíolos con más de $50 \%$ de su área dentro del cuadro de alambre fueron contadas y promediadas. Con base en la cantidad promedio de bases persistentes del pecíolo en 25 $\mathrm{cm}^{2}$ y el área total del tallo (longitud del tallo $\times$ perímetro promedio) se obtuvo una aproximación del total de bases persistentes para cada individuo. La edad se obtuvo al dividir el total de bases persistentes entre el número promedio de hojas producidas anualmente por un individuo promedio (Lázaro-Zermeño, 2002). Si los tallos eran pequeños el total de las bases persistentes se contó directamente. Con el fin de documentar la intensidad de la cosecha de hojas (conteo de hojas removidas por planta, número de plantas cosechadas y número de peregrinos) desde 2004 se ha participado en las juntas de organización de los peregrinos y en la realización de las actividades de remoción de hojas en el campo.

\section{Resultados}

Relaciones filogenéticas y distribución de Zamiaceae. Las especies del orden Cycadales constituyen el grupo de gimnospermas dioicas más antiguo y son consideradas como el primer grupo de plantas con semillas (Chamberlain, 1915; Mamay, 1969; Eckenwalder, 1980; Brenner et al., 2003; Nagalingum et al., 2011). Actualmente, la distribución de las especies de Cycadales se restringe a las regiones tropicales (ocasionalmente subtropicales) de Australia, este de Asia, centro y sur de África, México, Centroamérica, Sudamérica y las Antillas Mayores y una especie en Japón (Jones, 1993; Donaldson et al., 2003; Whitelock, 2002; Walters et al., 2004). Se estima que existen aproximadamente 314 especies de Cycadales en todo el mundo (Hill et al., 2007).

El orden Cycadales incluye las familias Cycadaceae, Stan- 
geriaceae y Zamiaceae. La familia Zamiaceae es la más abundante y diversificada e incluye a los géneros Ceratozamia, Chigua, Dioon, Encephalartos, Lepidozamia, Macrozamia, Microcycas y Zamia (Donaldson et al., 2003). De acuerdo con Mabberley (2008) se han descrito hasta 160 especies de Zamiaceae a nivel mundial. Sin embargo, Stevenson et al. (2003) y Hill et al. (2007) solamente reconocen 89 especies, de las cuales indican que 47 se distribuyen en México, seis en Cuba y el resto en países centroamericanos. Sin embargo, Haynes (2011) recientemente menciona para México 62 especies. El género Dioon incluye 14 especies (NicolaldeMorejón et al., 2009; Haynes, 2011), de las cuales 13 son especies endémicas a México, distribuidas entre los $14^{\circ}$ y $29^{\circ}$ de latitud norte, en los estados de Sinaloa, Durango, Nayarit, Jalisco, Colima, Michoacán, Guerrero, Oaxaca y Chiapas, en la vertiente del Pacífico, y en los estados de Tamaulipas y Veracruz en la vertiente del golfo de México (Gregory y Chemnick, 2004; González-Astorga et al., 2003; NicolaldeMorejón et al., 2009). Solamente D. mejiae Standl. \& L.O. Williams ha sido reportada como endémica de Honduras (Sabato y De Luca, 1985), aunque Stevenson et al. (2003) y Bonta et al. (2006) la mencionan también para Nicaragua.

Descripción botánica de Dioon merolae. La presente descripción se basa en la original en latín para la especie publicada por De Luca et al. (1981) complementada con observaciones originales y de la literatura. Dioon merolae De Luca, Sabato y Vázquez-Torres (De Luca et al., 1981) consta de un tronco cilíndrico, erecto o inclinado, de $3 \mathrm{~m}$ o más de altura, con diámetro de $25-40 \mathrm{~cm}$. Pueden presentarse uno o más tallos secundarios unidos a una misma base que no rebasan los $3.5 \mathrm{~m}$ de longitud, y cada tallo puede producir su copa de hojas y eventualmente ramificar en su porción distal. El tallo está poco lignificado debido a que el córtex y la médula son abundantes y el xilema ocupa sólo una pequeña porción entre ellos; el floema también es escaso y está formado por tejido parenquimatoso y fibras. El córtex está atravesado por numerosas trazas foliares, algunas directas y otras que forman una faja interna. Los canales por donde circula el mucílago se sitúan cercanos a la corteza (Chamberlain, 1911). La especie muestra catafilos densamente lanosos ca. $10 \mathrm{~cm}$ de largo y con bases de $2 \mathrm{~cm}$ de ancho. Las frondas son planas, numerosas, coriáceas, ascendentes, tomentosas cuando jóvenes al madurar glabras, de $100 \mathrm{~cm}(-140 \mathrm{~cm})$ de largo. El raquis es semi-cilíndrico, recto o irregularmente retorcido; pecíolo semi-cilíndrico de 7-10 cm de largo y con base de $2-3 \mathrm{~cm}$ de ancho. Folíolos subopuestos, numerosos (120 o más), linear-lanceolados, con un aguijón, insertados oblicuamente sobre el raquis, imbricados con excepción de los basales, márgenes revolutos, adelgazándose hacia la base, el ápice tendiente a espinuloso. Folíolos inferiores de $1 \mathrm{~cm}$ de largo y $2 \mathrm{~mm}$ de ancho, gradualmente más grandes, margen entero o con un aguijón; folíolos de la parte media 7-9 $\mathrm{cm}$ de largo, 10-12 mm de ancho, ca. 20 nervios, márgenes enteros o con 1-2 aguijones de $1 \mathrm{~mm}$ de largo en la parte superior; los folíolos superiores gradualmente decreciendo hasta $1.5-2.0 \mathrm{~cm}$ de largo y $3 \mathrm{~mm}$ de ancho, márgenes inferiores enteros o dentados, con uno o rara vez dos aguijones, márgenes superiores con 1-4 aguijones de $1 \mathrm{~mm}$ de largo. Dioon merolae produce sus estructuras reproductivas en el ápice de los tallos. Los megaestróbilos emergen entre marzo y mayo, pueden ser fertilizados entre agosto y diciembre durante un periodo individual de fertilidad de tres semanas. El megaestróbilo es ovoide de $45 \times 25 \mathrm{~cm}$ y pesa en promedio $3.6 \mathrm{~kg}( \pm 1.97, n=6$; aunque se han encontrado conos de más de $6.4 \mathrm{~kg}$ ), ápice agudo; las escamas son lanceoladas de 10-12 $\times 4-5 \mathrm{~cm}$, densamente lanosas en su exterior. El microestróbilo es alargado cilíndricamente, de (20-) 30-40 $(-60) \times 8-10 \mathrm{~cm}$; pueden emerger en cualquier época del año y se desarrollan completamente en un lapso de siete meses y pesan en promedio $216 \mathrm{~g}( \pm 128.0, n=10)$. Los microesporofilos con la base angosta de $2.5 \mathrm{~cm}$ de largo; la parte fértil bilobada, la parte estéril hacia arriba con un ángulo menor a $30^{\circ}$ del eje (parte esterili sursum arrecta; De Luca et al., 1981), con una proyección curva terminada en punta en su mitad superior. Las semillas son ovoides, de $3 \mathrm{~cm}$ de diámetro y pueden producirse entre 107 y 149 semillas por cono, con un peso promedio de $14.4 \mathrm{~g}( \pm 1.8, n=154)$ cada una (Lázaro-Zermeño, 2002). Las semillas pueden desprenderse del cono generalmente a los ocho meses después de la polinización, en algunos casos hasta 22 meses después. Las semillas están cubiertas por una sarcotesta almidonosa y aromática de color amarillo. Al caerse la sarcotesta y si el embrión se ha desarrollado completamente, la semilla puede germinar de inmediato. Las semillas son recalcitrantes y, por tanto, no forman bancos de semillas.

Distribución geográfica de Dioon merolae. La especie se distribuye en poblaciones aisladas en Oaxaca, en la Sierra Madre del Sur, la Sierra de Juárez, los Valles Centrales, en las regiones de Tehuantepec y Los Chimalapas (Chemnick et al.,

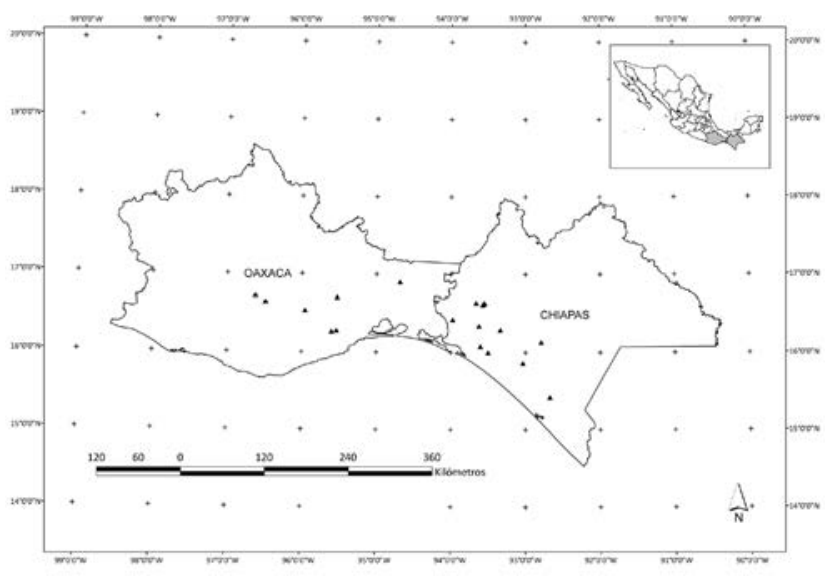

Figura 1. Distribución de las poblaciones de Dioon merolae en Chiapas y Oaxaca, México. 
1997; Flores-Vázquez, 2008) y en al menos 12 poblaciones en dos regiones fisiográficas de Chiapas (sensu Müllerried, 1957): la Depresión Central de Chiapas (municipios de Cintalapa, Jiquipilas, La Concordia y Villaflores) y la Sierra Madre de Chiapas, en los municipios de Arriaga y Tonalá (De Luca et al., 1981; Lázaro-Zermeño, 2002) (Figura 1). Las características generales de la geología, clima, suelos, vegetación y uso del suelo en cada región se concentran en el Cuadro 1.

En las poblaciones de Chiapas se ha observado que los individuos adultos de Dioon merolae sólo se distribuyen en las partes media y alta de laderas de pendiente moderada $\left(18-25^{\circ}\right)$, principalmente en las laderas de orientación norte de montículos insulares rocosos o promontorios que se elevan abruptamente sobre una planicie o una pendiente suave (conocidos en la nomenclatura geomorfológica internacional como inselberg), con suelos muy delgados y ligeros y dosel muy abierto (Lázaro-Zermeño, 2002; González-Espinosa et al., 2012) (Figura 2A, B). Las plántulas y los individuos infantiles $(<25 \mathrm{~cm}$ de altura) se distribuyen cerca de la planta madre, en oquedades profundas y en la cercanía de taludes

Cuadro 1. Resumen de condiciones del hábitat en las regiones en que se encuentran poblaciones de $D$. merolae en Oaxaca y Chiapas. SMS = Sierra Madre del Sur, SJ = Sierra de Juárez, VCO = Valles Centrales de Oaxaca, IST = Istmo de Tehuantepec - Distrito Tehuantepec, SS $=$ Sierra Sur de Oaxaca - Distrito Yautepec, CHI = Istmo de Tehuantepec - Distrito Juchitán (Los Chimalapas), DCCH = Depresión Central de Chiapas, $\mathrm{SMCH}=$ Sierra Madre de Chiapas, $\mathrm{mda}=$ millones de años, $N=$ tamaño estimado de la población, incluyendo plántulas. Las regiones fisiográficas de Chiapas corresponden a las propuestas por Müllerried (1957). La clasificación de climas regionales corresponde a García (1987), TMA = temperatura media anual; $\mathrm{SBC}=$ Selva baja caducifolia, $\mathrm{BE}=$ Bosque de encino, $\mathrm{BP}=$ Bosque de pino, $\mathrm{BPE}=$ Bosque de pino-encino.

\begin{tabular}{|c|c|c|c|c|c|c|c|c|}
\hline Región & $\begin{array}{l}\text { Altitud } \\
(\mathrm{m})\end{array}$ & $\begin{array}{l}\text { Sustrato } \\
\text { geológico }^{5}\end{array}$ & $\begin{array}{l}\text { Climas } \\
\text { regionales }^{6}\end{array}$ & $N$ & $\begin{array}{l}\text { Tipos de } \\
\text { suelos }^{5}\end{array}$ & $\begin{array}{l}\text { Atributos de } \\
\text { los suelos }\end{array}$ & $\begin{array}{l}\text { Vegetación } \\
\text { original y grado } \\
\text { de disturbio }\end{array}$ & $\begin{array}{l}\text { Uso actual } \\
\text { del suelo }\end{array}$ \\
\hline $\mathrm{SMS}^{1}$ & 1,150 & $\begin{array}{l}\text { Gneis del } \\
\text { Precámbrico, } \\
\text { calizas del } \\
\text { Cretácico }\end{array}$ & $\begin{array}{l}\text { Aw2, cálido sub-húmedo } \\
\text { con lluvias en verano } \\
(500-2,500 \mathrm{~mm}) \text { y } \\
\text { TMA de } 18-22^{\circ}\end{array}$ & $\approx 400$ & $\begin{array}{l}\text { Regosol, } \\
\text { rendzina }\end{array}$ & $\begin{array}{l}\text { Someros, textura } \\
\text { fina, fertilidad baja, } \\
\text { color rojizo }\end{array}$ & BPE; severo & $\begin{array}{l}\text { Cultivos de } \\
\text { fríjol y maíz }\end{array}$ \\
\hline$S J^{1}$ & 1,080 & $\begin{array}{l}\text { Calizas, lutita - } \\
\text { arenisca del } \\
\text { Jurásico }\end{array}$ & $\begin{array}{c}C(w 2) x^{\prime}, \text { templado } \\
\text { sub-húmedo con lluvias } \\
\text { en verano }(200-1,800 \\
\text { mm) y TMA de } 12 \\
\text { a } 18^{\circ} \mathrm{C} .\end{array}$ & $\approx 100$ & $\begin{array}{l}\text { Regosol, } \\
\text { cambisol }\end{array}$ & $\begin{array}{l}\text { Someros, textura } \\
\text { fina, fertilidad baja, } \\
\text { color claro a rojizo }\end{array}$ & $\begin{array}{l}\text { BPE, BP; } \\
\text { moderado }\end{array}$ & $\begin{array}{l}\text { Cultivos de } \\
\text { maíz y café }\end{array}$ \\
\hline $\mathrm{VCO}^{2}$ & $\begin{array}{l}1,600- \\
1,700\end{array}$ & $\begin{array}{l}\text { Metamórficas del } \\
\text { Precámbrico, } \\
\text { calizas del } \\
\text { Mesozoico }\end{array}$ & $\begin{array}{c}(A) C b\left(w_{o}\right)(w) \text {, semicálido } \\
\text { sub-húmedo con lluvias } \\
\text { en verano }(600-700 \mathrm{~mm}) \\
\text { TMA de } 18-20^{\circ}\end{array}$ & $\approx 470$ & $\begin{array}{l}\text { Feozem, } \\
\text { regosol, } \\
\text { litosol }\end{array}$ & $\begin{array}{c}\text { Someros, textura } \\
\text { fina y media, fertilidad } \\
\text { moderada, color } \\
\text { pardo oscuro }\end{array}$ & $\begin{array}{l}\mathrm{SBC}, \mathrm{BE} ; \\
\text { bajo }\end{array}$ & Potreros \\
\hline $\mathrm{IST}^{1}$ & $\begin{array}{l}800- \\
1000\end{array}$ & $\begin{array}{l}\text { Calizas, limolita y } \\
\text { areniscas del } \\
\text { Mesozoico (ca. } \\
250 \mathrm{mda})\end{array}$ & $\begin{array}{c}\text { Aw2, cálido sub- húmedo } \\
\text { con lluvias en verano } \\
\text { (500 - } 2,500 \mathrm{~mm}) \text { y } \\
\text { TMA de } 18-22^{\circ}\end{array}$ & ND & $\begin{array}{l}\text { Regosol, } \\
\text { litosol, } \\
\text { luvisol }\end{array}$ & $\begin{array}{l}\text { Profundos, color } \\
\text { pardo, textura fina } \\
\text { o media, fertilidad } \\
\text { moderada }\end{array}$ & $\begin{array}{l}\mathrm{SBC} ; \\
\text { severo }\end{array}$ & $\begin{array}{l}\text { Ganadería, } \\
\text { cultivos de } \\
\text { maíz, frijol } \\
\text { y chile }\end{array}$ \\
\hline $\mathrm{SS}^{1}$ & 1,500 & $\begin{array}{l}\text { Ígneas extrusivas } \\
\text { del Cenozoico, } \\
\text { calizas, limolita - } \\
\text { arenisca del } \\
\text { Mesozoico }\end{array}$ & $\begin{array}{l}B S 1\left(h^{\prime}\right) w, \text { semi seco } \\
\text { cálido }(600-800 \mathrm{~mm}) \\
\text { y TMA mayor de } 22^{\circ}\end{array}$ & ND & $\begin{array}{l}\text { Luvisol, } \\
\text { cambisol }\end{array}$ & $\begin{array}{l}\text { Someros, textura } \\
\text { media, fertilidad } \\
\text { media, color } \\
\text { rojo a claro }\end{array}$ & $\begin{array}{l}\mathrm{BE}, \mathrm{SBC} \\
\text { severo }\end{array}$ & $\begin{array}{c}\text { Cultivos de } \\
\text { maguey }\end{array}$ \\
\hline $\mathrm{CHI}^{1}$ & 810 & $\begin{array}{l}\text { Ígneas intrusivas, } \\
\text { granito del } \\
\text { Paleozoico }\end{array}$ & $\begin{array}{l}\text { Am }(f) \text {, cálido húmedo } \\
\text { con lluvias de verano } \\
(2,000-2,500 \mathrm{~mm}) \text { y } \\
\text { TMA de } 22^{\circ}-24^{\circ}\end{array}$ & ND & $\begin{array}{l}\text { Regosol, } \\
\text { litosol, } \\
\text { acrisol }\end{array}$ & $\begin{array}{l}\text { Someros, textura } \\
\text { media o gruesa, } \\
\text { fertilidad baja, } \\
\text { color oscuro }\end{array}$ & $\begin{array}{l}\text { BPE, SBC; } \\
\text { moderado }\end{array}$ & $\begin{array}{l}\text { Ganadería, } \\
\text { explotación } \\
\text { forestal, cultivos } \\
\text { de maíz y frijol }\end{array}$ \\
\hline $\begin{array}{l}\mathrm{DCCH} \\
3,4\end{array}$ & $\begin{array}{l}550- \\
800\end{array}$ & $\begin{array}{l}\text { Areniscas del } \\
\text { Triásico y Jurásico } \\
\text { (ca. } 190 \text { mda) }\end{array}$ & $\begin{array}{c}A(f) \text {, cálido sub-húmedo } \\
\text { con lluvias de verano } \\
\text { (700 - } 1,000 \mathrm{~mm} \text { entre } \\
\text { mayo y octubre) y } \\
\text { TMA de } 25.3^{\circ}\end{array}$ & 1000 & $\begin{array}{l}\text { Litosol, } \\
\text { regosol }\end{array}$ & $\begin{array}{l}\text { Someros, textura } \\
\text { gruesa, fertilidad } \\
\text { baja, color rojizo }\end{array}$ & $\begin{array}{l}\mathrm{SBC}, \mathrm{BE} ; \\
\text { severo }\end{array}$ & $\begin{array}{l}\text { Cultivos de maíz } \\
\text { y cacahuate; } \\
\text { potreros con } \\
\text { quemas anuales }\end{array}$ \\
\hline $\begin{array}{l}\mathrm{SMCH} \\
3,4\end{array}$ & $\begin{array}{l}800- \\
1,300\end{array}$ & $\begin{array}{c}\text { Ígneas intrusivas y } \\
\text { metamórficas del } \\
\text { Paleozoico } \\
\text { (ca. } 280 \mathrm{mda})\end{array}$ & $\begin{array}{c}A(w) \text {, cálido húmedo } \\
\text { con lluvias en verano } \\
(2,000-2,500 \mathrm{~mm}) \\
\text { y TMA de } 18^{\circ}-22^{\circ}\end{array}$ & $\approx 300$ & $\begin{array}{l}\text { Litosol, } \\
\text { regosol, } \\
\text { rendzina, } \\
\text { luvisol }\end{array}$ & $\begin{array}{c}\text { Someros, textura } \\
\text { media, fertilidad } \\
\text { baja, color rojizo }\end{array}$ & $\begin{array}{l}\text { SBC, BPE; } \\
\text { moderado } \\
\text { y severo }\end{array}$ & $\begin{array}{l}\text { Extracción de } \\
\text { madera y leña, } \\
\text { potreros, cultivos } \\
\text { de maíz }\end{array}$ \\
\hline
\end{tabular}

${ }^{1}$ Chemnick et al. (1997), , ${ }^{2}$ Flores-Vázquez (2008), ${ }^{3}$ De Luca et al. (1981), ${ }^{4}$ Lázaro-Zermeño (2002), ${ }^{5}$ INEGl (2007), ${ }^{6}$ Arriaga et al. (2000), ${ }^{7}$ Miranda (1952), Miranda y Hernández X. (1963) 
(< 10 m; González-Espinosa et al., 2012). En las partes bajas de los montículos, donde los terrenos son casi planos y la profundidad del suelo es mayor de $40 \mathrm{~cm}$, a menudo se encuentran plántulas asociadas con gramíneas y especies arbóreas, aunque muy pocas llegan a establecerse como individuos adultos, posiblemente debido a la competencia por agua y luz. En la Depresión Central de Chiapas, los individuos de tallas pequeñas representan $30 \%$ de la población, respecto al $11 \%$ reportado para una de las poblaciones de los Valles Centrales de Oaxaca (Flores-Vázquez, 2008).

Crecimiento del tallo principal y producción de retoños y ramas. El incremento en la longitud del tallo se aprecia cuando hay producción de hojas. Cuando los individuos de Dioon merolae son pequeños, el tallo es subterráneo y sólo ocurre el crecimiento en grosor, resultado de la expansión del córtex y de la producción de primordios foliares (Stevenson, 1980). La elongación empieza a hacerse evidente una vez que el tallo alcanza $-15 \mathrm{~cm}$ de diámetro. En los primeros diez años de vida el incremento en la longitud del tallo es menor de $1.0 \mathrm{~cm}$ por año; posteriormente, conforme los individuos incrementan en longitud, la cantidad de hojas producidas también aumenta provocando que el incremento anual del tallo sea de $2-3 \mathrm{~cm}$. Cuando las plantas crecen debajo de riscos, cornisas, grietas o cerca de taludes o de árboles y arbustos cercanos, donde la luz puede ser escasa en las horas del día en las que los rayos del sol inciden en ángulos bajos, los tallos muestran un acentuado fototropismo y gravitropismo y se curvan e inclinan conforme crecen (Figura 2C) hasta que acaban por postrarse sobre el suelo (González-Espinosa et al., 2012).

La producción de retoños (o fitómeros) puede iniciarse cuando el tallo principal alcanza los $50 \mathrm{~cm}$ de longitud (1-6 retoños por año). Se ha observado que las plantas masculinas pueden presentar hasta seis veces más retoños que las femeninas (34 vs. 6 retoños). Los retoños tienen hojas pequeñas (40 cm o menos) y tienen vida corta, generalmente menos de tres años. Sin embargo, algunos llegan a desarrollarse como tallos laterales con su propia copa de hojas, unidos en su base al tallo principal con el cual comparten un único sistema radical. Algunos individuos muy longevos pueden llegar a tener hasta 18 tallos además del tallo principal (Figura 2D). En la parte media y alta del tallo se encuentran meristemos que pueden dar origen a ramas cada una con su propia copa de hojas. La longitud que alcanzan las ramas es mucho menor que la de un tallo $(<100 \mathrm{~cm})$; sin embargo, al desarrollarse también producen su propia copa de hojas. Los individuos de poblaciones severamente defoliadas pueden presentar con mayor frecuencia varias copas de hojas en el extremo del tallo, en comparación con individuos de poblaciones no cosechadas que generalmente poseen sólo una.

Raíces. El sistema radical incluye tres tipos de raíces (Jones,
1993). (1) La radícula da lugar a la raíz principal, que es tan profunda como lo permite el sitio en el que germinó la semilla; esta raíz es común a todos los tallos. (2) Las raíces adventicias se desarrollan, como la radícula, rápidamente durante el primer año de vida, alcanzando hasta $1.5 \mathrm{~m}$ de longitud (aunque no sean profundas) y aún cuando la planta no tenga un tallo visible. Este sistema radical superficial resulta eficiente durante el estrés hídrico al que están sujetas las plántulas en los meses de noviembre a abril. (3) Las raíces apogeotrópicas o coraloides (Chamberlain, 1935) se desarrollan cuando el tallo alcanza $5 \mathrm{~cm}$ de longitud, crecen de modo dicotómico y también se encuentran casi expuestas a la superficie del suelo. Su función es fijar el nitrógeno atmosférico mediante la asociación simbiótica con algas azul-verde de los géneros Anabaena, Nostoc y Tolypothrix (Chamberlain, 1935; Milindasuta, 1975; Argüello-López, 2007).

Producción de hojas. Las hojas se disponen helicoidalmente en el extremo del tallo y forman una copa (Norstog y Nicholls, 1997). En las poblaciones observadas las hojas se producen en un pulso anual en los meses de marzo y abril, antes del inicio de la temporada lluviosa (mayo a noviembre). Sin embargo, puede ocurrir un segundo evento de producción de hojas en el otoño si algún incendio destruye las copas al final de la temporada seca (abril o mayo); en este caso, no se ha observado producción de hojas en la primavera siguiente. Las hojas recién producidas son suaves y tomentosas en ambas superficies de los folíolos. Después de unos dos meses, el tomento cae y las hojas se tornan rígidas y adquieren una consistencia coriácea (Figura 2E). El desarrollo de las frondas se completa en un lapso adicional no mayor a tres meses con la consolidación de espinas apicales y laterales. La vida de las hojas individuales es generalmente de dos años. Las plántulas e infantiles producen una hoja al año, en algunos casos hasta por 12-15 años; los individuos con tallos de más de $10 \mathrm{~cm}$ de longitud producen de dos a diez hojas al año hasta alcanzar la etapa reproductiva. Los individuos adultos producen 30-40 hojas en un único pulso anual que contribuyen a formar una copa de hasta 150 hojas.

Reproducción. Todas las especies del orden Cycadales son dioicas (Stevenson et al., 1995). La proporción de sexos en los individuos de Dioon merolae es cercana a 1:1, con un ligero sesgo hacia los individuos masculinos (LázaroZermeño et al., 2011). A diferencia de otras zamiáceas en las que los individuos masculinos pueden producir conos femeninos, y viceversa, después de soportar largos periodos de estrés hídrico o altas temperaturas (van Wyk y Claassen, 1981; Osborne, 1985; Osborne y Gorelick, 2002), en D. merolae no se ha encontrado reversión de sexos a pesar de estar sujetos a este tipo de factores ambientales. Aunque la edad de $D$. merolae puede ser imprecisa, estimamos que los individuos que empiezan a reproducirse pueden tener entre 80 y 100 años (véase apartado acerca del cálculo de la edad). 
Conos masculinos.- Los individuos con tallos mayores a $70 \mathrm{~cm}$ pueden producir microestróbilos (conos masculinos) (Figura 2F). Si durante la etapa reproductiva muere alguno de los tallos más grandes de un individuo adulto, los tallos pequeños $(>50 \mathrm{~cm})$ pueden también producir conos del mismo sexo. Generalmente, cada individuo produce un cono en cada evento reproductivo, aunque en raros casos (menos del 2\%) se producen dos conos a la vez. Los conos

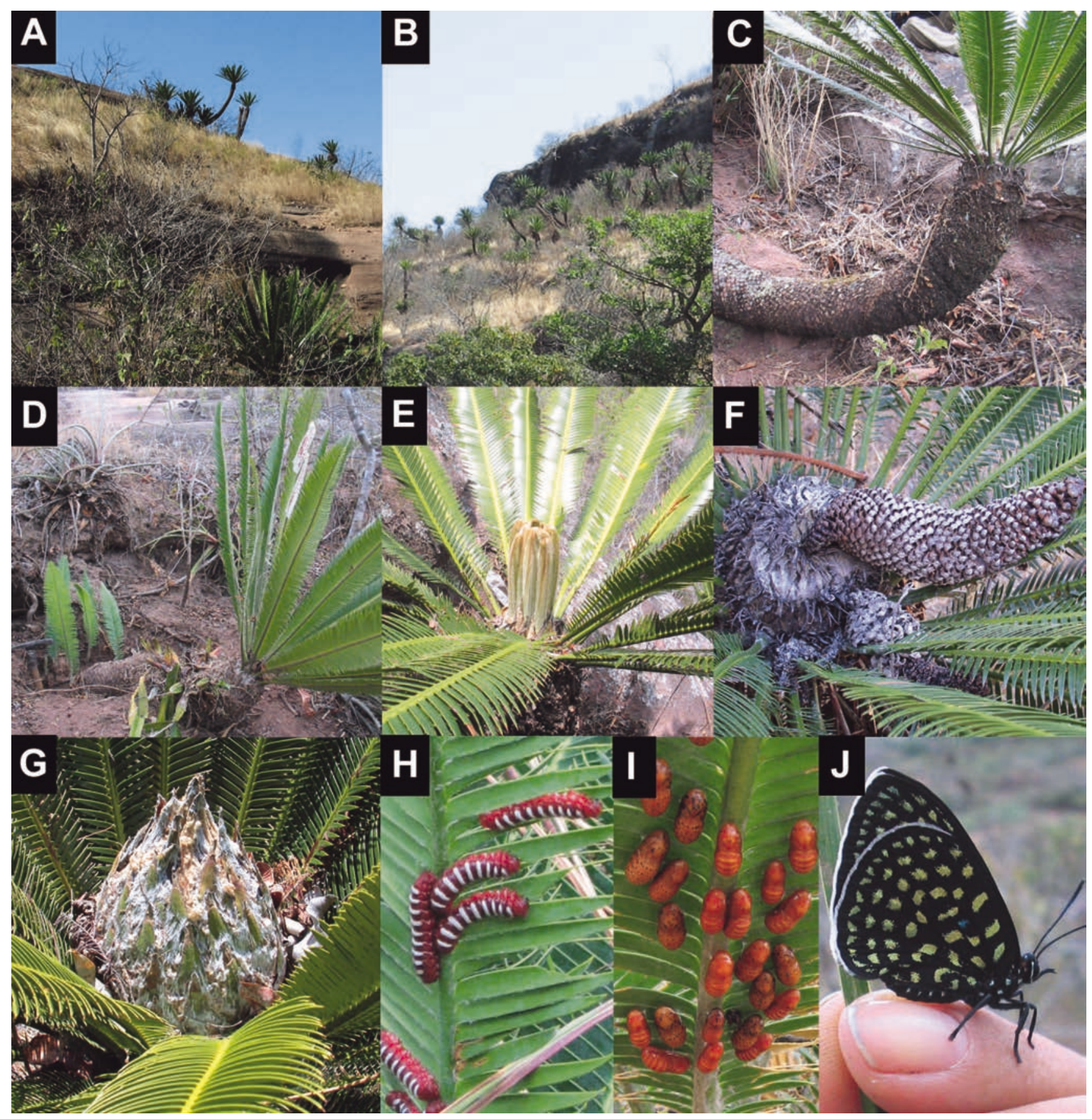

Figura 2. A y B) Distribución de los individuos de Dioon merolae sobre los montículos de areniscas en las poblaciones de la Depresión Central de Chiapas. C) Planta de D. merolae creciendo junto a un talud; nótese la pronunciada inclinación del tallo por la heliofilia de la copa. D) Individuo adulto postrado en el suelo; en la base del tallo se pueden observar al menos cuatro retoños, cada uno con una hoja recién producida. E) Individuo adulto de D. merolae que muestra las hojas nuevas en el centro de la copa. F) Microestróbilo, ca. 40 cm de largo. G) Megaestróbilo inmaduro, ca. $30 \mathrm{~cm}$ de largo. H-J). Larvas, pupas y adulto de Eumaeus debora sobre los folíolos de D. merolae. (Créditos de las fotografías: JMLZ. excepto F y G por N. Ramírez-Marcial) 
masculinos están conformados por microesporófilas dispuestas en espiral de manera compacta sobre un eje hueco, son poco tomentosos, de color verde amarillento cuando jóvenes y pardo oscuro cuando maduros. La emergencia de conos masculinos puede ocurrir en cualquier época del año y su desarrollo completo se alcanza en siete meses, miden 40-60 cm de longitud y muy rara vez se encuentran conos pequeños con polen (10 cm de longitud). Las microesporófilas se abren al completarse el desarrollo del cono y con ello se promueve la circulación ascendente de las corrientes de viento (Niklas y Norstog, 1984; Keppel, 2001) y la subsecuente liberación y dispersión del polen, el cual también es dispersado por coleópteros (Norstog y Fawcett, 1989; Jones, 1993; Mabberley, 2008). El polen no dispersado queda esparcido sobre las hojas como un polvo blanquecino.

Conos femeninos.- Los megaestróbilos (conos femeninos) (Figura 2G) comienzan a desarrollarse hasta que el tallo alcanza al menos $90 \mathrm{~cm}$ de longitud. De manera similar a lo que ocurre en los individuos masculinos, cuando un individuo reproductivo presenta varios tallos y por alguna razón el tallo más grande muere, los tallos pequeños $(>70 \mathrm{~cm})$ tienen la facultad de producir conos femeninos. Los conos son de forma ovoide y de color ocre a causa del denso tomento que los cubre. La emergencia de conos ocurre comúnmente en la estación lluviosa, de mayo a octubre. Al principio, el cono emerge y se desarrolla erecto en el ápice del tallo y muchos de los conos se desarrollan completamente en esta posición, pero en algunos casos el corto pecíolo se inclina debido al peso del cono y éste termina desarrollándose en uno de los costados del tallo. En promedio los conos femeninos tardan 13 meses para completar su desarrollo. El tiempo de receso entre eventos reproductivos puede durar dos años, pero en algunas especies, como Dioon edule, puede ser de hasta cuatro años (Vovides, 1990). En una población de D. merolae de la Depresión Central de Chiapas en la que las plantas femeninas son defoliadas anualmente, los individuos tardan hasta seis años en volver a producir un cono femenino (Lázaro-Zermeño, 2011). A diferencia de los individuos masculinos, los individuos femeninos no pueden producir simultáneamente conos y hojas en el mismo año.

Interacciones con animales. Herbivoría.- Las hojas y semillas, e incluso las raíces y tallos de las Cycadales no son comestibles para la mayoría de los animales por contener sustancias tóxicas y cancerígenas (Moretti et al., 1981; Hoffman y Morgan, 1984; Spencer et al., 1987; OliveiraCruz, 2001; Mejía y Rengifo, 2000; Yagi, 2004; Pérez-Flores y Soto, 2007; Marler y Shaw, 2010). Entre estas sustancias se incluyen las cicasinas y las neosicasinas, derivadas del grupo de los azoxiglucósidos (metilazoximetil- -Dglucósidos; Kobayashi et al., 1978), las macrozaminas, derivadas del metilazoximetanol (MAM; Moretti et al., 1981), los aminoácidos no proteicos, -N-metilamino-L-alanina, y -N-oxilamino-L-alanina (BMAA y BOAA, respectivamente; Vega y Bell, 1967; Shaw et al., 2007); los esteroles estigmasterol (SS) y -sitosterol (BSS) y sus derivados glucosilados: estigmasterol -D-glucósido (BG) y -sitosterol -D-glucósido (BSSG) (Marler y Shaw, 2010). La herbivoría foliar en Dioon merolae ocurre en los meses de enero a mayo, cuando las mariposas Eumaeus debora Hubner (Lepidoptera: Lycaenidae) (C. Castillo-Guevara, com. pers.) ovipositan sobre las hojas nuevas. Las orugas se desarrollan de manera simultánea con las hojas, y consumen preferentemente los folíolos, aunque también se alimentan del raquis destruyendo completamente la hoja (Figura 2H-J). La defoliación causada por las orugas comprende la eliminación de 40-100\% del área fotosintética recién producida, lo cual puede afectar el vigor de los individuos dado que la planta produce hojas sólo una vez al año (Lázaro-Zermeño, 2002). En algunas ocasiones, se han encontrado orugas de E. debo$r a$ alimentándose de los megaesporófilos (brácteas) del cono femenino. Esta mariposa podría secuestrar e incorporar a su cuerpo las sustancias tóxicas presentes en $D$. merolae, tal como ocurre con E. atala Poey y Zamia integrifolia L.f., nativa de Florida (Rothschild et al., 1986; Schneider et al., 2002).

Polinización y producción de semillas.- La dispersión del polen en Cycas, Dioon y Zamia se debe principalmente al viento (Niklas y Norstog, 1984; Norstog y Nicholls, 1997), aunque Norstog (1987) sugirió la posibilidad de que la polinización por insectos (Curculionidae) puede ocurrir en todas las Cycadales de manera prioritaria o en combinación con la polinización por viento. No se dispone de observaciones detalladas que indiquen que los insectos que visitan los conos masculinos de D. merolae contribuyan a la polinización. Al parecer, la polinización es un aspecto de la biología reproductiva que no ha sido abordado de manera suficiente en ninguna de las zamiáceas mexicanas. Una vez que el cono femenino ha completado su desarrollo, que casi siempre coincide con la temporada de estiaje, las brácteas que lo forman empiezan a separarse unas de otras debido a la deshidratación provocada por el ambiente. Al momento de caer del cono, las semillas están cubiertas por una excrecencia almidonosa y aromática de color amarillo llamada sarcotesta. La sarcotesta, cuando fresca, es removida por insectos, principalmente hormigas; también puede resecarse y adherirse a la esclerotesta, parte dura de la semilla que encierra el embrión y las sustancias de reserva, inhibiendo así la germinación (Whitelock, 2002).

Germinación de semillas.- Cuando el embrión se ha desarrollado completamente, la semilla puede germinar de inmediato si se expone a condiciones favorables (Pérez-Farrera et al., 1999); estos mismos autores indican que las semillas no presentan latencia por embrión inmaduro, como varias especies de Ceratozamia y Zamia. Se observó > 80\% de germinación 
en las 200 semillas colectadas y tres meses después de la germinación las plántulas mostraron su primera hoja, la cual pudo mantenerse durante uno o dos años (Figura 3A,B). Pérez-Farrera et al. (1999) indican que la hoja alcanza su completo desarrollo y endurecimiento seis meses después.

Depredación de semillas.- El embrión puede ser dañado por coleópteros y roedores, impidiéndose con ello la germinación. Los coleópteros (Aulacoscelis melanocera Duponchel $\&$ Chevrolat (Chrysomelidae), Carpophilus spp. (Nitidulidae) y una especie no determinada de la familia Bituridae), fueron encontrados entre las brácteas de conos femeninos y horadando la esclerotesta para posteriormente ovipositar en el material de reserva; sus larvas suelen alimentarse de éste y del embrión. Por otra parte, pequeños roedores (Liomys pictus Thomas; Heteromyidae) pueden romper la esclerotesta, exponiendo el embrión a la intemperie y provocando así la inviabilidad de la semilla. Las plántulas de semillas que una vez desprendidas del cono germinan atrapadas en la copa de la planta progenitora no alcanzan a desarrollar la primera hoja; sólo se observa la emergencia de la radícula y mueren en los siguientes 30 días por falta de nutrimentos y agua. Junto con Dioon mejiae y D. spinulosum, las semillas de $D$. merolae son consideradas entre las más grandes del género (Sabato y De Luca, 1985).

Dispersión de semillas.- El principal mecanismo de dispersión para Dioon merolae en las poblaciones estudiadas es la gravedad. Cuando la planta madre crece en acantilados, las semillas caen en lugares abiertos, en cuyo caso las plántulas con frecuencia no se establecen debido a la intensa competencia con angiospermas (pastos) o por los incendios rasantes. Si la pendiente es suave, las semillas se alejan pocos metros de la planta madre; en pendientes pronunciadas se ha observado que las semillas pueden alejarse hasta 14 metros. En ambos casos, las semillas pueden quedar atrapadas por los troncos o las raíces de los árboles vecinos, o al caer en una oquedad. Pérez-Farrera (1993) ha reportado avistamientos de urracas (Calocitta formosa Swainson), y durante este estudio se observaron chachalacas (Ortalis vetula Wagler) picoteando los megaestróbilos e iguanas (Iguana iguana $\mathrm{L}$.) comiendo la sarcotesta de las semillas. Las semillas de $D$. merolae también han sido encontradas en pequeñas grietas, oquedades entre las rocas, comederos de zorras (Urocyon cinereoargenteus Schreber) o sobre nopales y bromelias junto con semillas de Thevetia ovata (Cav.) A. DC. (Apocynaceae), Bursera bipinnata (Sessé \& Moc. ex DC.) (Burseraceae) y Serjania triquetra Radkl. (Sapindaceae) (Figura 3C). Los roedores Liomys pictus pueden llevar las semillas a sus madrigueras o extraviarlas en rendijas entre las rocas. Sobre la esclerotesta de las semillas de D. merolae se han observado marcas de incisivos de L. pictus; estas dentelladas coinciden con las encontradas sobre las testas de $B$. $b i$ pinnata y T. ovata.
Los incendios y sus efectos sobre la supervivencia y reproducción. Desde hace varias décadas las tierras que circundan los montículos donde se distribuye Dioon merolae en Chiapas son utilizadas como potreros y para cultivos agrícolas de temporal y son limpiadas con la práctica tradicional de roza y quema. Ocasionalmente, los incendios sin control se extienden hasta las partes medias o altas de los montículos. Si el incendio es de poca intensidad y corta duración, las hojas y los tallos de los individuos de D. merolae resultan poco afectados; de lo contrario, el exterior de los tallos es calcinado (Figura 3D, E) y, ocasionalmente los individuos mueren. Pérez-Farrera y Vovides (2006) han señalado que en el sitio del cerro Nambiyigua (Sierra Madre de Chiapas) los incendios son deliberadamente provocados por grupos religiosos antagónicos e intolerantes a la ceremonia de los espadañeros; no se han encontrado evidencias de este conflicto en los sitios de la Depresión Central de Chiapas. Los incendios interrumpen de manera definitiva el desarrollo de conos y semillas. Cuando una planta que está produciendo cono se incendia, el cono no alcanza a desarrollarse debido a que los óvulos no alcanzaron a ser fecundados. En caso de que las semillas se encuentren dispersas en el suelo, las altas temperaturas ocasionan la muerte del embrión. Debido a que no cuentan con un tallo bien desarrollado, las plántulas y los individuos de tallas pequeñas enfrentan una mayor probabilidad de muerte que los adultos. Después de los incendios las plantas pequeñas que sobreviven quedan expuestas a intensidades lumínicas altas y al pisoteo por ganado. Posiblemente estos dos factores contribuyan a limitar la presencia de esta especie en áreas planas con suelos profundos.

Longevidad y cálculo de la edad. La muerte ocasional del tallo de mayor tamaño complica considerablemente la determinación de la edad de los individuos de Dioon merolae. Se encontró que los individuos con un tallo de 4.0 metros de longitud podrían tener al menos 700 años de edad y que individuos adultos con una altura de $100 \mathrm{~cm}$ (con capacidad de producir conos) pueden tener entre 80 y 100 años de edad.

Etnobotánica y conservación. El comercio ilegal con individuos adultos de zamiáceas es frecuente en su área de distribución. En algunas ciudades de los estados de Chiapas, Oaxaca y Veracruz se pueden encontrar vendedores ambulantes ofreciendo individuos de Dioon edule o partes de ellos (Donaldson et al., 2003). En Chiapas no es frecuente el comercio de individuos adultos o plántulas de $D$. merolae y no parece ser una amenaza para las poblaciones. Sin embargo, en esta entidad la destrucción del hábitat por cambio de uso de suelo representa un riesgo constante para esta especie. Una antigua tradición de la cultura chiapaneca (PérezFarrera y Vovides, 2006), que ahora también es practicada por grupos zoques (Valdez, 2009) y mestizos, denominada 

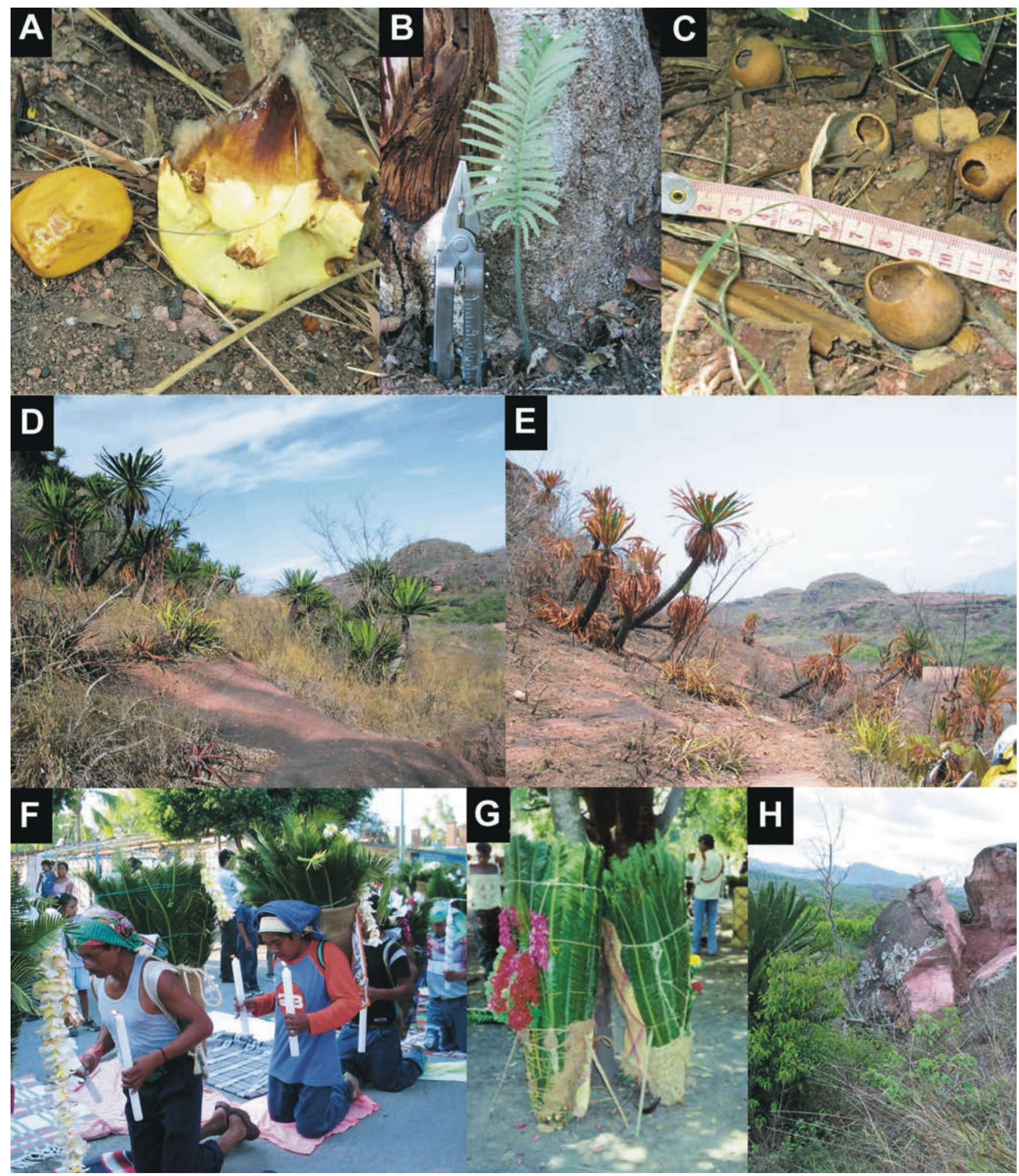

Figura 3. A) Semilla de Dioon merolae cubierta por sarcotesta amarilla; a la derecha, una bráctea del cono femenino. B) Plántula (un año de edad). C) Semillas de D. merolae roídas por Liomys pictus. D) Ladera con plantas de D. merolae de hasta $4.6 \mathrm{~m}$ de largo del tallo; nótese en primer plano el área con roca desnuda. E) Las mismas plantas después de un incendio severo ocasional ocurrido en mayo de 2006. F). "Espadañeros" entrando a la iglesia de San José Terán, Chiapas. G) Tercios de hojas (atados) de D. merolae en Suchiapa, Chiapas; cada tercio se forma con 300 hojas. H) Base de un montículo de areniscas con una planta adulta expuesta al daño por desprendimiento de la roca. (Créditos de las fotografías: JMLZ) 
de la Santa Cruz, representa una severa amenaza. Para la ceremonia los recolectores de hojas (espadañeros) con frecuencia desprenden hasta $100 \%$ de las hojas de individuos adultos (generalmente 1-2.5 $\mathrm{m}$ de altura), que al realizarse de manera anual repercute en el desempeño reproductivo y el tamaño de las hojas (Lázaro-Zermeño, 2011; Lázaro-Zermeño et al., 2011). En un estudio de cinco años realizado en una población anualmente defoliada, se encontró que los individuos femeninos de $D$. merolae se reproducen menos que los individuos no defoliados (Lázaro-Zermeño et al., 2011). Otros atributos vegetativos como el crecimiento del tallo y el número y tamaño de las hojas producidas también se ven afectados por las defoliaciones anuales que exceden la corta de hojas de 50\% (Lázaro-Zermeño, 2011; Lázaro-Zermeño et al., 2011). La festividad se realiza en las cabeceras municipales de Suchiapa y Terán y en el ejido Nuevo Tenochtilán en el municipio de Villaflores (Chiapas). Los peregrinos o espadañeros llevan a la iglesia decenas de ofrendas (tercios) que constan de 300 hojas de espadaña, nombre común que se le da a $D$. merolae (Figura $3 F, G$ ). Los espadañeros obtienen las hojas de los individuos que se distribuyen en los cerros El Estoraque y El Sauz en el municipio de Jiquipilas y en el cerro Nambiyigua, en el municipio de Villaflores. Dado que en estas poblaciones se encuentran sólo decenas de individuos adultos (menos de 200), cada vez se hace más difícil la cosecha de hojas por los incendios periódicos que, con frecuencia, queman las hojas e incluso causan la muerte de los individuos. Los espadañeros comentan que hace 2025 años las plantas se distribuían notoriamente en la falda del cerro Nambiyigua y que cada individuo presentaba una copa con más de cien hojas.

\section{Discusión}

Arquitectura y producción de retoños. La incidencia de la luz sobre la copa de individuos con tallos bien desarrollados influye en la arquitectura de la planta. Los individuos de Dioon merolae que se establecen en lugares plenamente expuestos al sol tienen tallos erectos. El fenómeno de curvatura e inclinación del tallo conforme avanza su edad sugiere que los individuos de D. merolae son altamente heliófilos, como se ha observado también en individuos de Cycas seemannii A. Braun (Keppel, 2001). La inclinación acentuada de los tallos en plantas adultas de $D$. merolae también puede activar los meristemos ubicados en la base del tallo, ya que el peso en uno de sus costados puede actuar como un estímulo mecánico, resultando en la producción de retoños que ocasionalmente pueden crecer y formar su copa de hojas (Chamberlain, 1911; Jones, 1993). Los montículos donde crece D. merolae con frecuencia son de areniscas o de otras rocas poco consolidadas y, a menudo, grandes fragmentos de roca caen de las partes altas dañando e incluso derribando individuos adultos que se encuentran establecidos en las partes bajas de las laderas (Figura 3H). Los individuos que crecen sobre la parte de roca que se desgaja se destruyen durante el descenso; en este caso, generalmente mueren y sólo rara vez pueden establecerse nuevamente. Aunque el tallo está protegido por catafilos (estructuras rígidas de ca. $2 \mathrm{~cm}$ de longitud que no llegan a desarrollarse como hojas verdaderas) y por las bases persistentes de los pecíolos, Jones (1993) sugiere que los meristemos son activados mediante estímulos físicos o ambientales. Las altas temperaturas generadas por el fuego también pueden activar los meristemos de la base del tallo. Se ha observado que el número de retoños en la base del tallo de individuos adultos aumenta después de un incendio; sin embargo, si el incendio es muy prolongado se eliminan los retoños ya existentes.

A pesar de que el tallo es flexible por no estar completamente lignificado (Chamberlain, 1911; Stevenson, 1980), la ruptura en la parte basal evidencia las limitaciones de tipo mecánico a las que están sujetos los tallos de grandes dimensiones (4-5 m). Es común que los individuos adultos pierdan uno o más tallos a causa de los incendios o de daños causados con machetes. Lo anterior puede no causar la muerte del individuo, pero sí conducirlo a un estado fenológico previo (p. ej. infantil o juvenil). Estos individuos "rejuvenecidos" pueden diferenciarse de otros de edad menor por el tamaño y número de las hojas que producen. Los tallos remanentes no dañados pueden producir mayor cantidad de hojas, $\mathrm{y}$ éstas son más grandes respecto a las hojas producidas por un individuo juvenil que ha crecido a partir de una semilla. El individuo (un genet sensu Kays y Harper, 1974) con varios tallos basales (retoños o ramets sensu Kays y Harper, 1974), puede persistir por más tiempo de lo que permanecería un individuo monopódico. Stevenson (1980) y Jones (1993) mencionan que las Cycadales no poseen, en general, yemas laterales y por ello no producen ramas en un sentido estricto. Aunque la producción de fitómeros o retoños basales da lugar a considerar que $D$. merolae sea una especie clonal (como la mayoría de las Zamiaceae), no parece que éste sea un mecanismo común que permita el crecimiento poblacional y ocupación del espacio, pues no se observa la supervivencia de los tallos desprendidos del sistema radical de manera natural. Se desconoce si en condiciones de vivero los retoños de $D$. merolae pueden desarrollar raíces y crecer por sí solos una vez que son separados del tallo principal, lo cual permitiría su propagación, como ha ocurrido con otras especies de Cycadales (Dehgan, 1997; J. Haynes, com. pers.).

Producción de hojas y reproducción. Los eventos de producción de hojas y producción de conos femeninos se observan de manera alternada en años diferentes en Dioon merolae. Esto puede deberse a que las hojas y los conos de ambos sexos tienen el mismo origen en el ápice del tallo (Kozlowski, 1971) y posiblemente ejercen una demanda común sobre los recursos internos disponibles, junto con interacciones entre la estacionalidad del ambiente y el lapso necesario para la 
producción del cono femenino (13 meses en promedio). A lo largo de un año en que se produce un cono femenino no alcanzan a producirse hojas. A diferencia de los individuos femeninos, los masculinos, cuyos conos se producen en un periodo promedio de siete meses, pueden alcanzar a producir conos (menos costosos) y hojas en un mismo año. Aunque la producción de conos masculinos es constante durante el año, algunos conos femeninos no llegan a desarrollarse por completo aun cuando se encuentran cerca de individuos masculinos, supuestamente en condiciones favorables para la polinización, resultando en pequeños conos sin semillas.

Interacciones con animales. En adultos de Dioon merolae se puede observar que cuando la temperatura ambiental excede $34^{\circ} \mathrm{C}$ se desprende un poco de mucílago en la base de los conos masculinos, el cual atrae a escarabajos picudos (Cucurlionidae), hemípteros, mariposas (Licaenidae) y hormigas pequeñas. Estos insectos se mueven hacia dentro y fuera entre las microesporófilas y al hacerlo se cubren de polen; sin embargo, no se dispone de observaciones detalladas acerca de si estos insectos con polen sobre sus cuerpos pueden visitar conos femeninos y contribuir a la polinización. De acuerdo con Terry et al. (2007) y Tang (1987), los terpenos (mircenos y ocimenos) contenidos en el mucílago de Macrozamia lucida L.A.S. Johnson y Zamia pumila L. contribuyen al síndrome de polinización ya que son sustancias con funciones similares a las feromonas.

En la actualidad no es claro qué grupo de animales serían los dispersores óptimos de Dioon merolae. Considerando el tamaño de los animales que se han observado en interacción con las semillas de $D$. merolae, sería poco probable que una semilla fuera dispersada por endozoocoria. La asociación de esta especie con mamíferos pequeños y aves y reptiles de tamaño medio parece oportunista y poco ajustada. En el caso de las semillas movidas por roedores de tamaño medio o grande, no todas ellas son depredadas, y como ocurre en especies del género Quercus (Quintana-Ascencio et al., 1992; Bonfil, 1998), algunas que son olvidadas en las madrigueras pueden germinar posteriormente. Los roedores de tamaño medio Liomys pictus parecen efectuar la dispersión de $D$. merolae accidentalmente, ya que el daño sobre las semillas ocurre en la esclerotesta, sin alcanzar al embrión, de manera similar a lo reportado por Snow y Walter (2007) para la interacción de Macrozamia lucida L.A.S.Johnson con Rattus fuscipes Waterhouse en Queensland, Australia. Si el daño va más allá de la esclerotesta, éste es suficiente para promover la contaminación del material de reserva por hongos y bacterias e incluso ocasionar la muerte del embrión. En la mayor extensión del área de distribución de $D$. merolae se ha presentado en el último siglo un severo proceso de defaunación que ha ocasionado la casi extinción regional o alteración severa de las poblaciones de mamíferos de tamaño medio o grande como el venado cola blanca Odocoileus virginianus Zimmermann, los pecaríes Pecari tajacu Linnaeus y Tayassu pecari Link (Naranjo et al., 2005) y cánidos y mustélidos que podrían mover las semillas con sarcotesta. Finalmente, el tamaño de las semillas puede asociarse con megafauna extinta que pudo realizar su dispersión por endozoocoria (Janzen y Martin, 1982; Janzen, 1986), como también se ha sugerido para M. lucida (Snow y Walter, 2007). La antigüedad de las Cycadales sugiere que en otros periodos pudieron mantenerse prolongadas interacciones con dispersores ahora extintos, como se ha sugerido para un amplio conjunto de especies vegetales neotropicales que mantienen aparentes anacronismos ecológicos entre sus frutos y las poblaciones de animales que podrían dispersarlos (Janzen y Martin, 1982; Janzen, 1986; Barlow, 2000).

Estimación de la edad. Chamberlain (1911) propuso un método no destructivo para evaluar la edad que consiste en registrar el número total de hojas producidas en un año, contar el número total de cicatrices foliares persistentes en el tronco y dividir este número entre el número de hojas producidas en ese año. De esta manera Chamberlain (1911) estimó que individuos de Dioon edule con un tallo de $1.8 \mathrm{~m}$ de longitud tendrían una edad de 970 años. Vovides (1990) introdujo modificaciones al método propuesto por Chamberlain (1911), reportando estimaciones de la edad de $D$. edule obtenidas mediante dos métodos. El primero consiste en obtener una muestra de xilema de la base del tallo a partir del cual se determina la presencia de carbono $14\left(\mathrm{C}^{14}\right)$ contenido en la celulosa. El segundo método estima indirectamente la edad a partir de la producción de conos, la tasa de crecimiento anual del tallo y el espaciamiento entre eventos reproductivos. Sin embargo, las técnicas empleadas dañan el ápice del tallo exponiéndolo a infecciones fúngicas y suponen que el espaciamiento entre los eventos reproductivos de décadas recientes puede extrapolarse a toda la longitud del tallo. La técnica de fechado con $\mathrm{C}^{14}$ produjo estimaciones muy discrepantes respecto a las del ápice, explicadas por contaminación nuclear.

La estimación de la edad utilizada en este estudio es conservadora debido a: (1) aunque se producen hojas durante los primeros años de vida no hay bases persistentes de los pecíolos pues el tronco no se ha desarrollado, (2) al envejecer las bases persistentes pueden comprimirse disminuyendo su tamaño, (3) durante los eventos reproductivos la producción de hojas es baja o nula. Los troncos muy inclinados pueden desprenderse de la base de la planta y perecer; sin embargo, las partes enterradas de la planta se mantienen vivas durante una edad hasta ahora no calculada con base en estructuras externas. En el momento actual se diseña un estudio para evaluar las edades máximas de $D$. merolae con base en el $\mathrm{C}^{14}$ presente en las partes subterráneas de plantas de más de $4 \mathrm{~m}$ de altura.

Recomendaciones para un manejo sustentable. Actualmente el número de plantas vivas y de hojas en cada planta han 
disminuido debido a la cosecha anual mal planificada. Solamente los individuos distribuidos en lugares de difícil acceso, como las partes altas de los montículos y acantilados, han quedado fuera del alcance de los grupos de espadañeros (unas 40 personas por grupo, que colectan cada una 200300 hojas). Lo anterior ha provocado que los espadañeros busquen nuevas localidades para seguir con la tradicional cosecha de hojas. Algunas de las poblaciones de Dioon merolae localizadas en el municipio de Jiquipilas han estado sometidas a la cosecha anual de hojas por más de 25 años, pero a partir de la disminución de individuos de D. merolae en el cerro Nambiyigua, la afluencia de espadañeros a los sitios de El Estoraque y El Sauz ha aumentado y con ello la cosecha de hojas. A dos kilómetros de El Sauz se encuentran tres poblaciones más que han sido cosechadas sólo esporádicamente debido a que los individuos están distribuidos en lugares de difícil acceso.

La conservación de poblaciones viables de Dioon merolae no sólo depende del grado de conservación del hábitat sino también del uso que actualmente reciben. Aunque los individuos de tallas pequeñas son más abundantes que los individuos adultos, la ausencia de un plan de manejo para estos últimos que pudiera presentarse a los espadañeros los expone también a la severa cosecha anual de hojas con las consecuencias negativas recientemente documentadas en cuanto a reducción de la reproducción y del tamaño de las hojas (Lázaro-Zermeño, 2011; Lázaro-Zermeño et al., 2011). Los grupos de espadañeros saben que la existencia de la especie es crucial para la celebración de su festividad, pero no tienen claro cómo usar moderadamente este recurso. Además de mantener y promover algunos pequeños viveros establecidos en Chiapas desde 1995 para producir plantas de D. merolae (Vovides et al., 2002b; Vovides et al., 2010), que han servido para reintroducir plántulas en algunos municipios (Pérez-Farrera y Vovides, 2006; Chemnick y Pérez-Farrera, 2007) y para motivar acciones comunitarias para la conservación de este tipo de plantas, esto no parecería ser suficiente ante la presión actual que representa la severa defoliación anual de los individuos adultos. Además de promover el establecimiento de nuevos individuos que puedan ser cosechados en 50, 100 o más años, es urgente realizar talleres y otras actividades de educación ambiental con los espadañeros y los propietarios de los predios donde crece $D$. merolae para instruirles acerca de la necesidad de cosechar las hojas con menor frecuencia e intensidad (menos de 50\%) con base en resultados experimentales recientes (Lázaro-Zermeño, 2011). Aunque debe concederse que se han dado algunas acciones favorables, en el mejor de los casos debiera contarse con un más amplio y continuo respaldo de las autoridades ambientales, y sobre todo de las eclesiásticas, en todos los municipios donde se distribuye la especie, para analizar y proponer prácticas de manejo sustentable del recurso que permitan seguir cosechando las hojas y evitar que las poblaciones de esta especie se acerquen cada vez más a la extinción.

\section{Agradecimientos}

Los autores agradecen a los ejidatarios de Andrés Quintana Roo, municipio de Jiquipilas Chiapas, las facilidades otorgadas para realizar las observaciones dentro de sus parcelas. A Jaime Alberto Jiménez Fernández, Carlos Ernesto Méndez Morales, Luis Felipe Martínez Jiménez, Francisco Javier Borraz Jonapá, Marisela Gómez Cristiani y Beatriz Adriana Pérez Espinosa, por su apoyo en la recolección de los datos en campo. Agradecemos al doctor Miguel Ángel Morón Ríos (Instituto de Ecología, A.C., Xalapa, Ver.) por su valioso apoyo con la identificación de las especies de insectos asociadas a D. merolae en este estudio. Agradecemos a Víctor Alonso Gómez López (Universidad de Ciencias y Artes de Chiapas) por la captura de Liomys pictus y a Jorge Bolaños (El Colegio de la Frontera Sur) por su determinación taxonómica. Agradecemos los valiosos comentarios de Pedro A. Quintana-Ascencio, Carlos Montaña Carubelli, Neptalí Ramírez Marcial, Ken Oyama, Mariana Hernández Apolinar y Javier Caballero Nieto. El doctor Mario Ishiki Ishihara (El Colegio de la Frontera Sur) realizó una revisión de la traducción de la descripción de la especie en latín. Este trabajo es parte de una tesis doctoral del Posgrado en Ciencias Biológicas de la Universidad Nacional Autónoma de México (UNAM), que se llevó a cabo gracias a que la primera autora recibió una beca del CONACyT (núm. 181349).

\section{Literatura citada}

Arriaga L., Espinoza J.M., Aguilar C., Martínez E., Gómez L. y Loa E. Coords. 2000. Regiones Terrestres Prioritarias de México, escala de trabajo 1:1,000, 000. Comisión Nacional para el Conocimiento y uso de la Biodiversidad,. México, D.F. <www. conabio.gob.mx/conocimiento/regionalizacion/doctos/terrestres.html>

Argüello-López A.M. 2007. Aislamiento y caracterización de cianobiontes de diversas zamias en Puerto Rico. Tesis de Maestría, Universidad de Puerto Rico, Mayagüez, 65 pp.

Barlow C. 2000. The Ghosts of Evolution: Nonsensical Fruits, Missing Partners, and other Ecological Anachronisms. Basic Books, Nueva York.

Bonfil C. 1998. The effects of seed size, cotyledon reserves, and herbivory on seedlings survival and growth in Quercus rugosa and Q. laurina (Fagaceae). American Journal of Botany 85:79-87.

Bogler D.J. y Francisco-Ortega J. 2004. Molecular systematic studies in cycads: evidence from trn $\mathrm{L}$ intron and ITS2 rDNA sequences. The Botanical Review 70:260-273.

Bonta M., Flores-Pinot O., Graham D., Haynes J. y Sandoval. G. 2006. Ethnobotany and conservation of tiusinte (Dioon mejiae Standl. \& L.O. Williams, Zamiaceae) in north-eastern Honduras. Journal of Ethnobiology 26:228-257.

Brenner E.D., Stevenson D.W., McCombie R.W., Katari M.S., Rudd S.A., Mayer K. F.X., Palenchar P.M., Runko S.J., Twigg R.W., Dai G., Martienssen R.A., Benfey P.N. y Coruzzi G.M. 2003. Expressed sequence tag analysis in Cycas, the most primitive living seed plant. Genome Biology 4:R78. 
<ncbi.nlm.nih.gov/pmc/articles/PMC329417/pdf/gb-2003-412-r78.pdf>

CabreraToledo D. 2009. Biología poblacional de dos cícadas mexicanas con distintos niveles de rareza. Tesis de Doctorado, Instituto de Ecología, A.C. Xalapa, 152 pp.

Challenger A. 1998. Utilización y Conservación de los Ecosistemas Terrestres de México: Pasado, Presente y Futuro. Comisión Nacional para el Conocimiento y Uso de la Biodiversidad/ Universidad Nacional Autónoma de México/Agrupación Sierra Madre, A.C., México, D.F.

Chamberlain C.J. 1911. The adult cycad trunk. Botanical Gazette. 52:81-104.

Chamberlain C.J. 1915. A phylogenetic study of cycads. Proceedings of the National Academy of Sciences of the USA 1:86-90.

Chamberlain C.J. 1935. Gymnosperms: Structure and Evolution. University of Chicago Press, Chicago.

Chemnick J., Gregory T.J. y Salas-Morales S. 1997. A revision of Dioon tomasellii (Zamiaceae) from western Mexico, a range extension of D. merolae, and clarification of D. purpusii. Phytologia 83:1-6.

Chemnick J. y Pérez-Farrera M.A. 2007. Dioon merolae. The Cycad Newsletter 30:8-10.

Dehgan B. 1997. Propagation and culture of cycads: a practical approach. Acta Horticulturae 486:123-131.

De Luca P., Sabato S. y Vázquez-Torres V.M. 1981. Dioon merolae (Zamiaceae), a new species from Mexico. Brittonia 33:179-185.

Donaldson J.S., Hill K.D. y Stevenson D.W. 2003. Cycads of the world: an overview. En: Donaldson J. Ed. Cycads: Status Survey and Conservation Action Plan, pp. 3-8. IUCN/SSC Cycad Specialist Group, Gland.

Eckenwalder J. 1980. The cycads: the prime of their lives. Bulletin of the Fairchild Tropical Garden 35:11-19.

Esparza-Olguín L.G. 2004. ¿Que sabemos de la riqueza en especies vegetales? Un enfoque genético-demográfico. Boletín de la Sociedad Botánica de México 75:17-32.

Flores-Vázquez J.C. 2008. Dinámica de las fases tempranas de desarrollo y genética de poblaciones de la cícada Dioon merolae en Los Taviches, Oaxaca. Tesis de Maestría, Universidad Nacional Autónoma de México, México, D.F., 88 pp.

García E. 1987. Modificaciones al Sistema de Clasificación Climática de Koeppen. Instituto de Geografía, Universidad Nacional Autónoma de México, México, D.F.

González-Astorga J., Vovides A.P. e Iglesias C. 2003. Morphological and geographic variation of the cycad Dioon edule Lindl. (Zamiaceae): ecological and evolutionary implications. Botanical Journal of the Linnean Society 141:465-470.

González-Espinosa M., Pérez-Espinosa B.A. y Ramírez-Marcial N. Distribución espacial y respuesta fototrópica de Dioon merolae (Zamiaceae) en poblaciones relictuales del centro de Chiapas, México. Botanical Sciences 90:63-72.

Gregory T.J. y Chemnick J. 2004. Hypotheses on the relationship between biogeography and speciation in Dioon (Zamiaceae). En: Walters T. y Osborne R. Eds. Cycad Classification: Concepts and Recommendations, pp. 137-148. CABI Publishing, Wallingford.

Guariguata M.R., Cronkleton P., Shanley P. y Taylor P.L. 2008. The compatibility of timber and non-timber forest product extraction and management. Forest Ecology and Management 256:1477-1481.

Haynes J.L. 2011. World list of cycads: a historical review. IUCN/
SSC Cycad Specialist Group. 37 pp. <cycadsg.org/publications/ Haynes-Historical-Review-of-World-List-of-Cycads-2011. pdf $>$ Consultado el 19 de enero de 2012.

Hill K.D., Stevenson D.W. y Osborne R. 2007. The world list of cycads. Memoirs of the New York Botanical Garden 97:454483.

Hoffman G.R. y Morgan R.W. 1984. Review: putative mutagens and carcinogens in foods. V. Cycad azoxyglycosides. Environmental Mutagenesis 6:103-116.

INEGI [Instituto Nacional de Estadística y Geografía] 2007. Mapa digital de México. Instituto Nacional de Estadística, Geografía e Informática. México, D.F. <galileo.inegi.org.mx/website/ mexico/viewer.htm> (Consultado el 10 de febrero de 2011).

IUCN [International Union for Conservation of Nature] 2001. $\mathrm{Ca}$ tegorías y Criterios de la Lista Roja de la IUCN. Versión 3.1. Comisión de Supervivencia de Especies de la IUCN. International Union for Conservation of Nature, Gland. <intranet.iucn. org/webfiles/doc/SSC/RedList/redlistcatspanish.pdf> (Consultado el 20 de febrero de 2011).

Janzen D.H. y Martin P.S. 1982. Neotropical anachronisms: the fruits the gomphotheres ate. Science 215:19-27.

Janzen D.H. 1986. Chihuahuan desert nopaleras: defaunated big mammal vegetation. Annual Review of Ecology and Systematics 17:595-636.

Jones D.L. 1993. Cycads of the World. Ancient Plants in Today's Landscape. Smithsonian Institution Press, Washington.

Kays S. y Harper J.L. 1974. The regulation of plant and tiller density in a grass sward. Journal of Ecology 62:97-105.

Keppel G. 2001. Notes on the natural history of Cycas seemannii (Cycadaceae). South Pacific Journal of Natural Science 19:3541.

Kobayashi A., Tadera K., Yagi F., Etoh Y. y Yasuda S. 1978. Chemical reduction of cycasin, the toxic glycoside of cycad. $M e$ mories of the Faculty of Agriculture Kagoshima University 15:159-166.

Kozlowski T.T. 1971. Growth and Development of Trees. Academic Press, Nueva York.

Lázaro-Zermeño J.M. 2002. Dinámica poblacional de Dioon merolae De Luca, Sabato y Vázquez Torres, en dos sitios de la Depresión Central de Chiapas, México. Tesis de Licenciatura, Universidad de Ciencias y Artes de Chiapas, Tuxtla Gutiérrez, $99 \mathrm{pp}$.

Lázaro-Zermeño J.M. 2011. Demografía, conservación y aprovechamiento de productos forestales no maderables: el caso de Dioon merolae (Zamiaceae) en Chiapas, México. Tesis de Doctorado, Universidad Nacional Autónoma de México, México, D.F. $130 \mathrm{pp}$.

Lázaro-Zermeño J.M., González-Espinosa M., Mendoza A. Martínez-Ramos M. y Quintana-Ascencio P.F. 2011. Individual growth, reproduction and population dynamics of Dioon merolae (Zamiaceae) under different leaf harvest histories in central Chiapas, México. Forest Ecology and Management 261:427439.

Mabberley D.J. 2008. Mabberley's Plant-book. A Portable Dictionary of Plants, their Classification and Uses. Cambridge University Press, Cambridge.

Mamay S.H. 1969. Cycads: fossil evidence of late Paleozoic origin. Science 164:295-296.

Marler T.E. y Shaw C.A. 2010. Distribution of free and glycosylates sterols within Cycas micronesica plants. Scientia Horticul- 
turae 123:537-542.

Mejía K. y Rengifo E. 2000. Plantas Medicinales de Uso Popular en la Amazonía Peruana. Agencia Española de Cooperación Internacional/Instituto de Investigaciones de la Amazonía Peruana, Lima.

Milindasuta B.E. 1975. Developmental anatomy of coralloid root in cycads. American Journal of Botany 62:468-472.

Miranda F. 1952. La Vegetación de Chiapas. Tomo I y II. Ediciones del Gobierno del Estado, Tuxtla Gutiérrez.

Miranda F. y Hernández-X. E. 1963. Los tipos de vegetación de México y su clasificación. Boletín de la Sociedad Botánica de México 28:29-179.

Moretti A., Sabato S. y Siniscalco-Gigliano G. 1981. Monosaccharide composition of the mucilages in Encephalartos Lehm. (Zamiaceae). Giornale Botanica Italiano 115:291-297.

Müllerried F.K.G. 1957. Geología de Chiapas. Ediciones del Gobierno del Estado de Chiapas, Tuxtla Gutiérrez.

Nagalingum N.S., Marshall C.R., Quental T.B., Rai A.S., Little D.P. y Mathews S. 2011. Recent synchronous radiation of a living fossil. Science 334: 796-799.

Naranjo E.J., Dirzo R., López Acosta J.C., Rendón-von Osten J., Reuter A. y Sosa-Nishizak O. 2009. Impacto de los factores antropogénicos de afectación directa a las poblaciones silvestres de flora y fauna. En: Dirzo R., González R. y March I.J. Coords. Capital Natural de México, Vol. II: Estado de Conservación y Tendencias de Cambio, pp. 247-276, Comisión Nacional para el Conocimiento y Uso de la Biodiversidad, México, D.F.

Naranjo-Piñera E., Lorenzo-Monterrubio C. y Horváth A. 2005. La diversidad de mamíferos en Chiapas. En: González-Espinosa M., Ramírez-Marcial N. y Ruiz-Montoya L. Coords. Diversidad Biológica en Chiapas, pp. 221-263, Plaza y Valdés, México, D.F.

Nicolalde-Morejón E.F. 2005. Circunscripción de las especies del complejo Zamia katzeriana (Zamiaceae-Cycadales). Tesis de Maestría, Instituto de Ecología, A.C. Xalapa, 48 pp.

Nicolalde-Morejón F., Vergara-Silva F., González-Astorga J., Vovides A.P. y Espinosa de los Monteros A. 2009. Reciprocal illumination of morphological characters upon a molecular hypothesis supports the proposal of a new species of cycad from Mexico. Systematics and Biodiversity 7:73-79.

Niklas K.J. y Norstog K. 1984. Aerodynamics and pollen grain depositional patterns of cycad megastrobili: implications on the reproduction on three cycad genera (Cycas, Dioon, Zamia). Botanical Gazette 145:92-104.

Norstog K. 1987. Cycads and the origin of insect pollination. American Scientist 75:270-279.

Norstog K.J. y Fawcett P.K.S. 1989. Insect-cycad symbiosis and its relation to the pollination of Zamia furfuracea (Zamiaceae) by Rhopalotria mollis (Curculionidae). American Journal of Botany 76:1380-1394.

Norstog K.J. y Nicholls T.J. 1997. The Biology of the Cycads. Cornell University Press, Ithaca.

Octavio-Aguilar P. 2009. Demografía y genética de poblaciones para tres localidades de Dioon edule Lindl. (Zamiaceae) en el estado de Veracruz, Tesis de Doctorado, Instituto de Ecología A.C. Xalapa, 105 pp.

Oliveira-Cruz C.M. 2001. Substâncias tóxicas ou anti-nutricionais dos alimentos para animais. Tesis de Maestría. Faculdade de Medicina Veterinária, Universidade Técnica de Lisboa, 47 pp.

Osborne R. 1985. Sex change in cycads: a hope for woodii? En- cephalartos 2:20-22.

Osborne R. y Gorelick R. 2002. Sex change in cycads. Palms and Cycads 76:10-15.

Pérez-Farrera M.A. 1993. Estudio sobre germinación en semillas de espadaña Dioon merolae De Luca, P., S. Sabato \& VázquezTorres (Zamiaceae). Tesis de Licenciatura, Universidad de Ciencias y Artes de Chiapas, Tuxtla Gutiérrez, 98 pp.

Pérez-Farrera M.A., Vovides A.P. y J. G. Álvarez-Moctezuma. 1999. A study on germination of the cycad Dioon merolae (Zamiaceae). The New Plantsman 6:214-218

Pérez-Farrera M.A. y Vovides A.P. 2004. Spatial distribution, population structure, and fecundity of Ceratozamia matudai Lundell (Zamiaceae) in El Triunfo Biosphere Reserve, Chiapas, Mexico. The Botanical Review 70:299-311.

Pérez-Farrera M.A. y Vovides A.P. 2006. The ceremonial use of the threatened "espadaña" cycad (Dioon merolae, Zamiaceae) by a community of the Central Depression of Chiapas, Mexico. Boletín de la Sociedad Botánica de México 78:107-113.

Pérez-Farrera M.A., Vovides A.P., Octavio-Aguilar P., GonzálezAstorga J., de la Cruz-Rodríguez J., Hernández-Jonapá R. y Maza-Villalobos-Méndez S. 2006. Demography of the cycad Ceratozamia mirandae (Zamiaceae) under disturbed and undisturbed conditions in a biosphere reserve of Mexico. Plant Ecology 187:97-108.

Pérez-Farrera M.A., Vovides A. P., González D., Hernández-Sandoval L. y Martínez M. 2007. Variación morfológica y genética del complejo Ceratozamia miqueliana H. A. Wendl. (Cycadales, Zamiaceae). Memories of New York Botanical Garden 97:519-539.

Pérez-Flores C. y Soto E. 2007. Neurotoxinas de cianobacterias en los alimentos. Elementos 66:47-50.

Peters C.M. 1996. The Ecology and Management of Non-Timber Forest Resources. World Bank Technical Papers Number 322. The World Bank, Washington, D.C.

Quintana-Ascencio P.F., González-Espinosa M. y Ramírez-Marcial N. 1992. Acorn removal, seedling survivorship, and seedling growth of Quercus crispipilis in successional forests of the highlands of Chiapas, Mexico. Bulletin Torrey Botanical Club 119:6-18.

Rothschild M., Nash R.J. y Bell E.A. 1986. Cycasin in the endangered butterfly Eumaeus atala florida. Phytochemistry 25:1853-1854.

Sabato S. y De Luca P. 1985. Evolutionary trends in Dion (Zamiaceae). American Journal of Botany 72:1353-1363.

Sánchez-Ramos G., Garza-Ocañas F. y Martínez-Avalos J.G. 2002. Distribution and plant fitness of chamal (Dioon edule Lindl.) (Zamiaceae) in three localities of the Sierra Madre Oriental, Tamaulipas, México. BIOTAM 13:27-36.

Secrétariat of the Convention on Biological Diversity. 2001. Sustainable Management of Non-Timber Forest Resources. CBD Technical Series No. 6, Montreal.

SEMARNAT [Secretaria del Medio Ambiente y Recursos Naturales] 2002. Norma Oficial Mexicana NOM-059- ECOL 2001. Protección ambiental - Especies nativas de México de flora y fauna silvestres - Categorías de riesgo y especificaciones para su inclusión, exclusión o cambio - Diario Oficial de la Federación $2^{\text {a }}$ Sección, 6 de marzo de 2002.

Schneider D., Wink M., Sporer F. y Lounibos P. 2002. Cycads: their evolution, toxins, herbivores and insect pollinators. $\mathrm{Na}$ turwissenschaften 89:281-294. 
Schutzman B. 2004. Systematics of Meso-American Zamia (Zamiaceae). En: Walters T. y Osborne R. Eds. Cycad Classification: Concepts and Recommendations, pp. 159-172. CABI Publishing, Wallingford.

Shaw C.A., Wilson J. M.B., Cruz-Aguado R., Singh S., Hawkes E.L., Lee V. y Marler T. 2007. Cycad-induced neurodegeneration in a mouse model of ALS-PDC: is the culprit really BMAA or is a novel toxin to blame? Memoirs of the New York Botanical Garden 97:286-307.

Snow E.L. y Walter G.H. 2007. Large seeds, extinct vectors and contemporary ecology: testing dispersal in a locally distributed cycad, Macrozamia lucida (Cycadales). Australian Journal of Botany 55:592-600.

Spencer P.S., Nunn P.B., Hugon J., Ludolph A.C., Ross S.M., Roy D.N. y Robertson R.C. 1987. Guam amyotrophic lateral sclerosis-Parkinsonism-dementia linked to a plant excitant neurotoxin. Science 237:517-522.

Stevenson D.W. 1980. Radial growth in cycadales. American Journal of Botany 67:465-475.

Stevenson D.W., Osborne R. y Hill K.D. 1995. The world list of cycads. En: Voster P. Ed. Proceedings of the $3^{\text {rd }}$ International Conference on Cycad Biology (Cycad Society of South Africa), Pp. 55-64, Cycad Society of South Africa, Pretoria.

Stevenson D.W., Vovides A. y Chemnick J. 2003. Regional overview: New World. En: Donaldson J. Ed. Cycads: Status Survey and Conservation Action Plan, pp. 31-47. IUCN/SSC Cycad Specialist Group, Gland.

Tang W. 1987. Insect pollination in the cycad Zamia pumila (Zamiaceae). American Journal of Botany 74:90-99.

Terry I., Walter G.H., Moore C., Roemer R. y Hull C. 2007. Odormediated push-pull pollination in cycads. Science 318:70.

Valdez U. 2009. La Flor de Espadaña en Terán: Ofrenda de los Hojeros a la Santa Cruz. Universidad Politécnica de Chiapas, Tuxtla Gutiérrez.

van Wyk A.E. y Claassen M.I. 1981. Sex reversal in Encephalartos umbeluziensis. Veld and Flora 67:120-122.

Vega A. y Bell. E.A. 1967. -amino- -methylaminopropionic acid, a new amino acid from seeds of Cycas circinalis. Phytochemistry 6:759-762.

Vovides A.P. 1983. Systematic studies on the Mexican Zamiaceae. I. Chromosome numbers and karyotypes. American Journal of Botany 70:1002-1006.

Recibido: 23 de febrero de 2011

Aceptado: 30 de julio de 2011
Vovides A.P., Rees J.D. y Vázquez-Torres M. 1983. Zamiaceae. Flora de Veracruz 26:1-31.

Vovides A.P. 1985. Systematic studies on Mexican Zamiaceae II. Additional notes on Ceratozamia kuesteriana from Tamaulipas, Mexico. Brittonia 37:226-231.

Vovides A.P. 1990. Spatial distribution, survival and fecundity of Dioon edule (Zamiaceae) in a tropical deciduous forest in Veracruz, Mexico with notes on its habitat. American Journal of Botany 77:1532-1543.

Vovides A.P., Etherington J.R., Dresser P.Q., Groenhof A, Iglesias C. y Flores-Ramirez J. 2002a. CAM-cycling in the cycad Dioon edule Lindl. in its natural tropical deciduous forest habitat in central Veracruz, Mexico. Botanical Journal of the Linnean Society 138:155-162.

Vovides A.P., Iglesias C., Pérez-Farrera M.A., Vázquez-Torres M. y Schippmann U. 2002b. Peasant nurseries: A concept for an integrated conservation strategy for cycads in México. En: Maunder M., Clubbe C., Hankamer C., y Groves M. Eds. Plant Conservation in the Tropics: Perspectives and Practices, pp. 421-444, Kew Publishing, Kew.

Vovides A.P., Pérez-Farrera M.A., González-Astorga J., González D., Gregory T., Chemnick J., Iglesias C., Octavio-Aguilar P., Avendaño S., Bárcenas C. y Salas-Morales S. 2003. An outline of our current knowledge on Mexican cycads (Zamiaceae, Cycadales). Current Topics in Plant Biology 4:159-174.

Vovides A.P., Pérez-Farrera M.A., González D. y Avendaño S. 2004. Relationships and phytogeography in Ceratozamia (Zamiaceae). En: Walters T. y Osborne R. Eds. Cycad Classification: Concepts and Recommendations, pp. 109-125, CABI Publishing, Wallingford.

Vovides A.P., Pérez-Farrera M.A e Iglesias C. 2010. Cycad propagation by rural nurseries in Mexico as an alternative conservation strategy: 20 years on. Kew Bulletin 65:603-611.

Walters T., Osborne R. y Decker D. 2004. "We hold these truths ..." En: Walters T. y Osborne R. Eds. Cycad Classification: Concepts and Recommendations, pp. 1-11, CABI Publishing, Wallingford.

Whitelock L.M. 2002. The Cycads. Timber Press, Portland.

Yagi F. 2004. Azoxyglycoside content and -glycosidase activities in leaves of various cycads. Phytochemistry 65:3243-3247. 